\title{
Factors Associated with Research Productivity among Oral Healthcare Educators in an Asian University
}

\author{
Bernardo E. Bay $\mathrm{Jr}^{1} \&$ Maria Eloisa C. Clerigo ${ }^{2}$ \\ ${ }^{1}$ Research and Statistics Center, Lyceum of the Philippines University-Batangas, Philippines \\ ${ }^{2}$ College of Dentistry, Lyceum of the Philippines University-Batangas, Philippines \\ Correspondence: Bernardo E. Bay Jr, Research and Statistics Center, Lyceum of the Philippines \\ University-Batangas, Philippines. E-mail: bernardbay25@yahoo.com
}

\author{
Received: July 4, 2013 Accepted: July 23, $2013 \quad$ Online Published: July 29, 2013 \\ doi:10.5539/ies.v6n8p124 URL: http://dx.doi.org/10.5539/ies.v6n8p124
}

This research is financed by Lyceum of the Philippines University-Batangas.

\begin{abstract}
Research writing confidence and organizational support toward research activities are two essential factors that may affect research productivity among higher educational institutions. This study investigated the possible relationships of these two factors to research productivity among faculty members of the College of Dentistry at Lyceum of the Philippines University-Batangas. The study used descriptive survey using percentage, weighted mean and Chi square to test the relationship of the selected variables.

The findings indicate that Dentistry faculty members have low research productivity as evidenced by its research production, with only five of them having completed a research paper as main author and only one as co-author (but, not the main author) from SY 2008-2009 to 2012-2013. Respondents agreed that, in average, institutional support is higher than the departmental support for conducting research paper. Meanwhile, respondents are most confident with the technical part in research writing, but least confident in writing the methodology. Organizational support given by the university itself and the Department of College of Dentistry towards research activities and faculty members' confidence in writing the paper particularly the technical and major parts were not indicators associated with research productivity. However, they are confident with the other parts of the research process including writing the abstract and references as associated with developing research findings.
\end{abstract}

Keywords: research productivity, research confidence, organizational support

\section{Introduction}

Research as required by the Commission on Higher Education (CHED) in the Philippines is among the three primary functions of all Higher Education Institutions (Nuqui and Cruz, 2012). Thus, administrators need to have a holistic understanding of how research should become integrated in their academic functions towards collaborative and reflective interventions.

With the new typology mandated by CHED, particularly putting research as agent towards human and social development, research productivity among educational institutions has significantly become an important element. It is used as a criterion for university status, center of excellence, autonomous/deregulated status, institutional quality, and opening of graduate programs (CHED Memorandum Order No. 25, Series of 1998, Priority Research Areas). Therefore, universities and colleges that are serious in transforming themselves into research institutions have to look at the elements of research culture that contribute to research productivity (Clemeña \& Acosta, 2008).

In 2009, a study by Wichian, Wongwanich, and Bowarnkitiwong found that research productivity was affected by direct correlation with the researchers' characteristics, research competence and institutional research-promoting characteristics. This implies that instructors who are capable in research skills and technique, funding skills, research management and research communication skills and networking and team-work would likely produce high research productivity. Since research activities or the popularity of research activities shore 
up university reputation (Idem, Berezi \& Akuegwu, 2012), any Higher Education Institution must ensure that it has a well defined research institutional program which serves as basis of developing its human resources to be ready and equipped with knowledge and skills to undergo research work (Alim \& Diocolano, 2011).

In Lyceum of the Philippines University (LPU), faculty members are required to do researches as part of their academic function and productive activities. To do this task, the management provides training and seminar for the faculty to enhance their research capabilities and increase their opportunities of involvement particularly in the conduct of research. This is the reason why the university has designed policy for research work describing the process of the research conduct with necessary mentoring and assistance to the faculty researchers. Apart from this, incentives and recognitions are also given to faculty researchers to motivate them in conducting research projects.

As the university aims to become a recognized university in the Asia Pacific Region by 2022 (LPU-B Manual), all disciplines must construe this vision by producing, disseminating and utilizing relevant research findings. However, based on the recent data compiled at the Research and Statistics Center, the College of Dentistry is among the low performers with regard to research productivity in terms of research output. Currently, the college has only five institutional and one action research completed for SY 2008-2009 to 2012-2013 (Research and Statistics Database), a five-year back statistics. Unfortunately, at present, there is little research evidence to support most clinical practice in oral healthcare, and many clinicians are unable to critically appraise research reports and other relevant literature. Thus, there is a need to ensure that in the future, all faculty members (and all other oral healthcare providers) should be competent in the critical appraisal of scientific literature relevant to their practice, and that some will have the ability to carry out research in primary care settings, such as their practices (Gray, 2007).

As initial step, it is indispensable to describe their confidence in writing the research paper to be able to identify what specific section in research writing needs retooling or enhancement. Likewise, it is important to assess the support given by the organization toward research programs and activities in order to motivate faculty members to conduct research. In this context, this study was conducted to assess whether organizational support and confidence in writing research are factors affecting the research productivity of the faculty members of the College of Dentistry.

\section{Objectives of the Study}

This study attempted to determine the factors affecting the research productivity among faculty members of the College of Dentistry. Specifically, this study aimed to identify the: (1) research productivity of the faculty in terms of the number of completed research report (2) faculty members' perceptions on the organizational support given to the faculty by the institution itself and their department towards research writing; (3) faculty members' self-assessment on their confidence toward research writing; (4) significant relationships among the research productivity, organizational support for research and research confidence toward research writing; and (5) plans for the enhancement of research productivity of the faculty members.

\section{Literature Review}

\subsection{Definition and Measurement of Research Productivity}

There has been no concrete definition of what research productivity is. Numerous studies were already conducted focused on this topic with various indicators of measurement. William, as cited by Wichian, et.al. (2009), noted that research productivity could be defined in terms of research product and research effort, to the extent of which a researcher produces. Most studies measured research productivity by calculating a composite indicator derived by summing up the number of finished research reports, number of published research reports, and number of utilized research report. The measurement of research productivity could be different, depending on the weights given to each indicator.

Individual research productivity is defined as output divided by career years. Wherein researcher's output is defined as the sum of the scores of all articles written over his or her career (Fabel, Hein \& Hofmeister, 2008). In the normal count, the productivity of each author and institution was calculated according to how many times they appeared in the database (Huang \& Hsu, 2005). Sax et al. as mentioned by Wician, et. al. (2009) estimated research productivity as an average number of published research report in the last two years. This study used researcher's role, publications in journals, research fund and the procedure of research as a surrogate for research productivity. 


\subsection{Factors Affecting Research Productivity}

\subsubsection{Intrinsic and Extrinsic Factors}

\subsubsection{Research Skills and Competence}

Research productivity according to Wichian, et. al. (2009) is affected by the research skills and technique under research competence. This was supported by Brambila, Veloso and Morgan (2007) who found that that there are significant differences in research productivity among areas of knowledge, not only in the peak of publications and citations but also in the productivity cycle. Wichian, et. al. also found that research experience and training in research gave better influence on research output utilization that research communication skills and networking and teamwork also affect research productivity.

Self-motivation, essential skills and experience are the fundamental drivers that encourage lecturers to do research. If there are no fundamental drivers, even the University provides other supportive factors, the University's efforts will be fruitless (Lertputtarak, 2008). Low research experience and skills which appear to be the cause of low research productivity in local or regional university, as The Noble University studied by Lertputtarak (2008) becomes also an evident problem in the said university. Therefore, it is suggested that factors related to the lecturers' personal improvement as researchers are essential.

Nuqui \& Cruz (2012) found consistent with some previous studies that researcher's characteristics and research competence are closely associated with research productivity. The effects further suggest that research competence may have more influence than researcher's characteristics on individual productivity. However, according to Kortlik, et. al. (2008), research confidence explains a major proportion of the variance in faculty research productivity.

\subsubsection{Tenure and Promotion Requirements}

Nuqui and Cruz (2012) found that faculty research productivity in Augustinian HEIs in Luzon is significantly influenced by the extent of research promotion of institutions in terms of promotion of the research environment and in providing mentors' assistance. Moreover, a study conducted by Nichols (2004) argued that those who have been employed by Extension for more than 10 years rated research expectations higher than those with fewer years did of service. Those individuals were also more likely to say that completing research projects is important in order to receive high merit on annual evaluations.

In case of Lyceum of the Philippines University-Batangas, faculty members are being classified using criteria including professional growth of which they are evaluated in terms of professional practice in related field of specialization, non-degree training program such as seminars, symposia, workshops, etc and published creative and scholarly works (LPU-B Manual).

\subsubsection{Organizational Support}

In structuring today's world of research, there is a need for substantial financial and technology resources, strict cost management, closer ties between public and private sector research, multidisciplinary and international research teams (Skills and Competencies..., 2010) and the funding skills and research management (Wichian, et. Al. 2009). According to the study of Alim and Diocolano (2011) institutional research objective, goals, agenda and priorities, network and linkages influence research output dissemination and utilization.

Among the management support, financial and technical support has very significant influence on research output dissemination at $1 \%$ level. Clear policies for research benefits and incentives also concern both the institution and CHED. Given the low salaries for faculty in majority of the HEIs in the country, providing adequate incentives becomes crucial in sustaining and enhancing research productivity (Clemeña \& Acosta, 2008). Furthermore, it is possible that the reward structure of the research establishment responds to initiatives like SNI, and researchers choose to allocate time to those activities that maximize future rewards (Brambila, et. al. 2007).

Similarly, programs can enhance research productivity with the incorporation of accountability features including formalized reports of progress and mentorship feedback in fellowship training. Facilitating the identification of a mentor and providing an additional year of research may be independent factors associated with research productivity (Cohen, Sherman, Kiet, Kapp, Osann, Chen, O’Sullivan, \& Chan, 2012) .

Moreover, it is imperative that the teachers of the future have the capacity to integrate research-based learning into their professional practice because of the context sensitive nature and rapidly evolving nature of teaching; without the capabilities to test new pedagogical approaches and understand their impact on learning, teachers have no way to determine the effectiveness of their strategies (Bower, 2010). However, if the University can 
provide supportive factors and lecturers that have plenty of willingness to do research, then it is most likely that significant research outcomes will be produced (Lertputtarak, 2008).

\section{Research Methodology}

\subsection{Research Design}

This research utilized the descriptive survey method. The survey method was used to describe the factors affecting the research productivity among the faculty members of the College of Dentistry.

\subsection{Participants}

The population for this study included all seven (7) full-time and four (4) part-time faculty members employed at the College of Dentistry of LPU-Batangas during SY 2012-2013. Female faculty comprised 7 of the respondents $(63.60 \%)$, and the rest were 4 male faculty members (36.40\%). Respondents under the age bracket of 31-40 and 41-50 years of age composed of $36.40 \%$. Most of them were married $(81.80 \%)$ and classified as Instructor $(45.50 \%)$ and mostly obtained bachelor's degree $(72.70 \%)$. The respondents were mostly 5 years as faculty members in the university.

\subsection{Instrument}

The scales and items that were used in the instrument were formulated based on the objectives and drawn after a review of the literature of the study. The face and content validity of the instrument were evaluated by an expert including the Council of Research Referees and Evaluators, Director for Research and Statistics and a Statistician. Changes that were recommended by the validation panel, and those identified as needed during the pilot test were incorporated into the instrument. These changes included the wording of items, the design of scales, and the instructions for completing the instrument. Internal consistency coefficient of .80 for the scales in the instrument was obtained using Cronbach's alpha. Responses were recorded on a four- point Likert scale that ranged from $1=$ Strongly Disagree to $4=$ Strongly Agree with the holistic interpretation of High, Average, Low and Very Low.

\subsection{Procedures}

The researchers adopted the questionnaire from the previous research of Pateña on research capabilities of faculty and student from different colleges in LPU-B. However, additional items were incorporated to assess the faculty self-assessment toward their research confidence and organizational culture/support for research scale using the standardized instrument used by Kortlik, et. al with some revisions to align with the set-up in the university. After a series of evaluation, pilot-testing and validation of the instrument, the researchers distributed them to the participants of the study and retrieved them for tallying, encoding and interpreting of the data.

\subsection{Statistical Treatment of the Study}

In describing the different variables in this study, percentage distribution was used to compute for the number of faculty members who completed researches as main author, co-author but served as the main author and co-author but not the main author. For this purpose, research productivity was calculated using the frequency distribution. The respondent was given a credit of 1.0 for every nature of involvement in the conduct of research. This was used as a surrogate for research productivity. For objectives number two and three, weighted mean was used to assess the research organizational support manifested by both institution and department and the faculty self-assessment toward their confidence in writing research. Meanwhile, Chi-square was used for objective number four to test the significant relationship among the selected variables.

\section{Results}

This section presents the analysis and interpretation of the data gathered from the participants of the study.

\subsection{Faculty Research Productivity}

Table 1. Individual research productivity

\begin{tabular}{lllll}
\hline & \multicolumn{2}{l}{ With Research Output } & \multicolumn{2}{l}{ Without Research Output } \\
\hline Productivity & $\mathrm{f}$ & $\%$ & $\mathrm{f}$ & $\%$ \\
Main author & 5 & 45.45 & 6 & 54.55 \\
Co-author (but, main author) & - & - & - & - \\
Co-author (but, not the main author) & 1 & 9.09 & 10 & 90.91 \\
\hline
\end{tabular}


Table 1 shows the research productivity of the faculty members. Information revealed that five faculty members produced researches as main author and one faculty as co-author (but, not the main author). Reflected from the data in the Research Office, most of the researches completed were institutional and were funded by the university.

\subsection{Research Organizational Support}

Table 2. Institutional support for research activities

\begin{tabular}{|c|c|c|c|}
\hline Institutional support & $\begin{array}{l}\text { Weighted } \\
\text { Mean }\end{array}$ & $\begin{array}{l}\text { Verbal } \\
\text { Interpretation }\end{array}$ & Rank \\
\hline $\begin{array}{l}\text { 1. The university offers competitive pay/honorarium in } \\
\text { conducting research }\end{array}$ & 3.27 & Agree & 4.5 \\
\hline $\begin{array}{l}\text { 2. The university provides enough budget for conducting } \\
\text { research }\end{array}$ & 2.91 & Agree & 10.5 \\
\hline $\begin{array}{l}\text { 3. The university provides sufficient in-house and outside } \\
\text { trainings to enhance my research competencies }\end{array}$ & 3.18 & Agree & 6 \\
\hline $\begin{array}{l}\text { 4. The university provides consultation services of adviser } \\
\text { (Dean, COREB, Research Council, Research Staff) }\end{array}$ & 3.27 & Agree & 4.5 \\
\hline $\begin{array}{l}\text { 5. The university provides enough services of } \\
\text { reader/referee }\end{array}$ & 3.45 & Agree & 2 \\
\hline $\begin{array}{l}\text { 6. The university provides enough services of the } \\
\text { editor/grammarian }\end{array}$ & 3.45 & Agree & 2 \\
\hline 7. The university provides enough statistical services & 3.45 & Agree & 2 \\
\hline $\begin{array}{l}\text { 8. The university offers more or improved office space or } \\
\text { facilities for conducting a research paper }\end{array}$ & 3.09 & Agree & 7 \\
\hline $\begin{array}{l}\text { 9. The university provides reliable internet access for } \\
\text { conducting a research paper }\end{array}$ & 3.00 & Agree & 8.5 \\
\hline $\begin{array}{l}\text { 10. The university provides access to online journals for } \\
\text { conducting a research paper }\end{array}$ & 2.91 & Agree & 10.5 \\
\hline $\begin{array}{l}\text { 11. The university offers recognition for individuals who } \\
\text { conduct research paper }\end{array}$ & 3.00 & Agree & 8.5 \\
\hline Composite Mean & 3.18 & Agree & \\
\hline
\end{tabular}

Legend: $3.50-4.00=$ Strongly Agree; $2.50-3.49=$ Agree; $1.50-2.49=$ Disagree; $1.00-1.49=$ Strongly Disagree

In terms of institutional support for research activities as reflected in Table 2, the respondents agreed that the university provides enough services of reader/referee (3.45), editor/grammarian (3.45) and statistical services (3.45) for the faculty researchers being the items with the highest weighted mean. This is a manifestation that the university effectively implements the process in conducting research wherein mentoring, advising and refereeing activities were clearly defined and integrated with. This, as further revealed in this study reflects the respondents' conviction that the university offers enough consultation services from adviser, Research Council, CORE members and Research staff (3.27).

Moreover, respondents agreed that the university offers competitive pay/honorarium in conducting research (3.27). This manifests that the faculty members are satisfied with the honorarium they receive for every research project they undertake. Honorarium for Institutional research is structured, based on the teaching rate of the researchers which accordingly a competitive rate. Given the low salaries for faculty in majority of the HEIs in the country, providing adequate incentives becomes crucial in sustaining and enhancing research productivity (Clemeña \& Acosta, 2008).

However, providing enough budget in conducting research, access to online journals and co-faculty's support to conduct research paper were rated lowest by the respondents as evidenced by their weighted mean of 2.91. Apart from the honorarium, the researcher receives budget incurred for refereeing, supplies, food and transportation wherein according to the respondents was least among the items. This may be due to the fact that they found the approved budget subsidy insufficient to pay for the expenses during the duration of the research conduct. Access to online journals was also rated least. The university subscribed only to one online journal the Academic One 
File which is accessible previously inside the university library only. In structuring today's world of research, there is a need for substantial financial and technology resources, strict cost management, closer ties between public sector and private sector research, multidisciplinary and international research teams (Skills and Competencies..., 2010) and the funding skills and research management (Wichian, et. al. 2009).

Table 3. Departmental support for research activities

\begin{tabular}{llll}
\hline Departmental support & $\begin{array}{l}\text { Weighted } \\
\text { Mean }\end{array}$ & $\begin{array}{l}\text { Verbal } \\
\text { Interpretation }\end{array}$ & Rank \\
\hline $\begin{array}{l}\text { 1. The department where I belong encourages me to } \\
\text { conduct a research report }\end{array}$ & 3.09 & Agree & 5 \\
$\begin{array}{l}\text { 2. The department where I belong recognizes my efforts to } \\
\text { conduct research report }\end{array}$ & 3.18 & Agree & 2 \\
$\begin{array}{l}\text { 3. The department where I belong supports my efforts to } \\
\text { conduct research report }\end{array}$ & 3.09 & Agree & 5 \\
$\begin{array}{l}\text { 4. The co-faculty in my department recognize my efforts } \\
\text { in conducting research paper }\end{array}$ & 3.00 & Agree & 8 \\
$\begin{array}{l}\text { 5. The co-faculty in my department support my efforts to } \\
\text { conduct research report }\end{array}$ & 2.91 & Agree & 9 \\
$\begin{array}{l}\text { 6. Collaborative conduct of research report with other } \\
\text { faculty in my department is encouraged }\end{array}$ & 3.27 & Agree & 1 \\
$\begin{array}{l}\text { 7. Collaborative conduct of research report within my } \\
\text { institution, but outside my department, is encouraged }\end{array}$ & 3.09 & Agree & 5 \\
$\begin{array}{l}\text { 8. Collaborative conduct of research report with } \\
\text { individuals from other institutions is encouraged }\end{array}$ & 3.09 & Agree & 5 \\
$\begin{array}{l}\text { 9. Collaborative conduct of research report with students } \\
\text { in my department is encouraged }\end{array}$ & 3.09 & Agree & 5 \\
Composite Mean & 3.09 & Agree & \\
\hline $\begin{array}{l}\text { Legend: } 3.50-4.00=\text { Strongly Agree; } 2.50-3.49=\text { Agree; } 1.50-2.49=\text { Disagree; } 1.00-1.49=\text { Strongly } \\
\text { Disagree }\end{array}$ & &
\end{tabular}

With regard to the support from the department as shown in Table 3, this study reveals that the department encourages faculty members to collaborate with other researchers to conduct research (3.27). As practiced in the university, collaboration or tie-up with other faculty member is one way of increasing the research involvement rating of the department. This strategy is adopted to maximize the time, financial support and effort in conducting research. In addition, collaboration benefits the researchers as it provides intellectual companionship and becomes a source of stimulation and creativity (Clarke and Preston, 2002).

However, co-faculty's support obtained the least rating due to respective personal commitment and engagement to their professional activities. This may also be due to the fact that co-faculty members are not confident to mentor co-faculty researcher because they themselves have low involvement in research activities. Faculty-to-faculty mentoring in research has yet to be introduced in the research culture in the university.

\subsection{Faculty self-Assessment to Their Confidence in Writing Research}

Table 4. Faculty self-assessment to research confidence in terms of technical

\begin{tabular}{|c|c|c|c|}
\hline $\begin{array}{l}\text { I am confident in writing the technical aspect in } \\
\text { writing research such as }\end{array}$ & $\begin{array}{l}\text { Weighted } \\
\text { Mean }\end{array}$ & Verbal Interpretation & Rank \\
\hline 1. research paper format & 2.73 & Agree & 3 \\
\hline 2. grammar and sentence construction & 2.82 & Agree & 1 \\
\hline 3. research organization & 2.73 & Agree & 3 \\
\hline $\begin{array}{l}\text { 4. communication skills (in writing and the conduct } \\
\text { of research data gathering, interview, etc.) }\end{array}$ & 2.73 & Agree & 3 \\
\hline Composite Mean & 2.75 & Agree & \\
\hline
\end{tabular}

Legend: $3.50-4.00=$ Strongly Agree; $2.50-3.49=$ Agree; $1.50-2.49=$ Disagree; $1.00-1.49=$ Strongly Disagree 
Table 4 shows the faculty self-assessment to research confidence in terms of technical. Technical aspect in writing research paper evolves on the paper format, grammar and sentence construction, research organization and communication skills.

Among the listed items, grammar and sentence construction obtained the highest weighted mean (2.82). Respondents agreed that they are confident on that aspect because of their background and previous know-how in grammar and sentence construction. Grammar and sentence construction are being taught and practiced as they perform their professional and teaching duties. Meanwhile, unlike with the rest of the items which got equal weighted mean of 2.73, special skills and trainings are required to perform well on those skills. Wichian (2009) found that research experience and training in research gave better influence on research output utilization; that research communication skills and networking and teamwork also affect research productivity.

Table 5. Faculty self-assessment to research confidence in terms of major parts (introduction)

\begin{tabular}{llll}
\hline $\begin{array}{l}\text { I am confident in writing the major parts in writing } \\
\text { research such as }\end{array}$ & $\begin{array}{l}\text { Weighted } \\
\text { Mean }\end{array}$ & Verbal Interpretation & Rank \\
\hline 1. writing the background & 2.64 & Agree & 4.5 \\
2. creating research problem & 2.73 & Agree & 2 \\
3. formulating theoretical / conceptual paradigm & 2.73 & Agree & 2 \\
4. formulating hypothesis & 2.73 & Agree & 2 \\
5. sources of literature review & 2.64 & Agree & 4.5 \\
6. conceptualizing research literature & 2.55 & Agree & 6 \\
Composite Mean & 2.73 & Agree & \\
\hline
\end{tabular}

Legend: $3.50-4.00=$ Strongly Agree; $2.50-3.49=$ Agree; $1.50-2.49=$ Disagree; $1.00-1.49=$ Strongly Disagree

Table 5 shows the faculty self-assessment with their confidence in writing the introduction of the paper. Among the items, creating research problem, formulating theoretical/conceptual paradigm and formulating hypothesis got the highest weighted mean (2.73). They agreed that these are the easiest part of the introduction since they serve as the direction and the rationale of the paper. These are all pre-conceptualized prior to the conduct proper. Conceptualizing research literature on the other hand became the least rated among the items. Literature serves as the support of the findings that were generated from the study (Pateña, 2012). Therefore, critical integration of studies in the paper is indispensable.

Table 6. Faculty self-assessment to research confidence in terms of major parts (methods)

\begin{tabular}{llll}
\hline $\begin{array}{l}\text { I am confident in writing the major parts in writing } \\
\text { research such as }\end{array}$ & $\begin{array}{l}\text { Weighted } \\
\text { Mean }\end{array}$ & Verbal Interpretation & Rank \\
\hline 1. develop research design & 2.77 & Agree & 1 \\
2. data collection & 2.75 & Agree & 2 \\
3. data entry (coding and cleaning) & 2.74 & Agree & 3 \\
4. sampling/ sample framework & 2.73 & Agree & 4.5 \\
5. constructing questionnaires & 2.64 & Agree & 6 \\
6. statistical tools / treatment & 2.55 & Agree & 7 \\
7. wording and ordering of questions & 2.73 & Agree & 4.5 \\
Composite Mean & 2.70 & Agree &
\end{tabular}

Legend: $3.50-4.00=$ Strongly Agree; $2.50-3.49=$ Agree; $1.50-2.49=$ Disagree; $1.00-1.49=$ Strongly Disagree 
As shown in table 6, respondents are most confident in developing research design, and data collection with 2.77 and 2.75 weighted means, respectively. Respondents agreed that they are most confident in developing the research design, since it serves as the defined approach to be used in the entire study. Data collection/retrieval and data entry are also manageable since they do it by themselves through scheduling and constant follow-up. However, respondents are least confident in terms of constructing questionnaire (2.64) and determining the appropriate statistical tools/treatment for the study. This is the reason why validation of instrument and statistical services are integrated in the research process to validate the instruments with the panel of reviewers/referees and statisticians during the refereeing stage. Similarly, with regard to statistical treatment, both college and institutional researches in the university are being performed by the appointed Statistician in the university. Therefore, faculty researchers have indirect and little involvement when it comes to statistical treatment and construction of the instrument.

Table 7. Faculty self-assessment to research confidence in terms of major parts (results and discussion)

\begin{tabular}{llll}
\hline $\begin{array}{l}\text { I am confident in writing the major parts in writing } \\
\text { research such as }\end{array}$ & $\begin{array}{l}\text { Weighted } \\
\text { Mean }\end{array}$ & Verbal Interpretation & Rank \\
\hline 1. presentation of gathered data & 2.73 & Agree & 2 \\
2. interpretation / analysis of results & 2.73 & Agree & 2 \\
3. correlation of literature to affirm results & 2.73 & Agree & 2 \\
Composite Mean & 2.73 & Agree & \\
\hline
\end{tabular}

Legend: $3.50-4.00=$ Strongly Agree; $2.50-3.49=$ Agree; $1.50-2.49=$ Disagree; $1.00-1.49=$ Strongly Disagree

When it comes to results and discussion, Table 7 shows that respondents agreed that they are equally confident in presenting the data gathered, in interpreting and in analyzing the results and in correlating literature to affirm results which got 2.73 weighted mean. This is where personal interpretations come in to elaborate the findings and to explain the generated results. Respondents further claim that they can simply provide insights, mainly when the study is loaded with related literature for affirmation or negation to the present findings of the study.

Table 8 . Faculty self-assessment to research confidence in terms of major parts (conclusion/recommendation)

\begin{tabular}{|c|c|c|c|}
\hline $\begin{array}{l}\text { I am confident in writing the major parts in writing } \\
\text { research such as }\end{array}$ & $\begin{array}{l}\text { Weighted } \\
\text { Mean }\end{array}$ & Verbal Interpretation & Rank \\
\hline 1. synthesizing results & 2.73 & Agree & 2 \\
\hline $\begin{array}{l}\text { 2. expressing additional value or importance to the } \\
\text { existing facts }\end{array}$ & 2.73 & Agree & 2 \\
\hline $\begin{array}{l}\text { 3. formulating recommendations to address the } \\
\text { research problem and concerns found in the study }\end{array}$ & 2.73 & Agree & 2 \\
\hline Composite Mean & 2.73 & Agree & \\
\hline
\end{tabular}

Legend: $3.50-4.00=$ Strongly Agree; $2.50-3.49=$ Agree; $1.50-2.49=$ Disagree; $1.00-1.49=$ Strongly Disagree

With regard to writing the conclusion and recommendation as shown in Table 8, the respondents agreed that they are also equally confident in terms of synthesizing results, expressing additional value or importance to the existing facts and formulating recommendations which got weighted mean of 2.73. Accordingly, respondents have equal confidence in formulating conclusion and in postulating recommendations and further directions of the research. 
Table 9. Faculty self-assessment to research confidence in terms of other parts (abstract)

\begin{tabular}{llll}
\hline I am confident in writing the other components in & $\begin{array}{l}\text { Weighted } \\
\text { Mriting reasearch such as }\end{array}$ & Verbal Interpretation & \multirow{2}{*}{ Rank } \\
\hline 1. clearly stating the research focus & 2.73 & Agree & 2.5 \\
2. summarizing the research methods used & 2.73 & Agree & 2.5 \\
3. outlining the results and discussion of the study & 2.73 & Agree & 2.5 \\
4. summarizing conclusion and recommendations & 2.73 & Agree & 2.5 \\
of the study & 2.64 & Agree & 5 \\
5. using the abstract format & 2.71 & Agree & \\
Composite Mean &
\end{tabular}

Legend: $3.50-4.00=$ Strongly Agree; $2.50-3.49=$ Agree; $1.50-2.49=$ Disagree; $1.00-1.49=$ Strongly Disagree

In terms of other components, particularly writing the abstract of the paper as shown in Table 9, respondents agreed that they are equally confident in stating the research focus, summarizing research methods used, outlining results and discussion and summarizing conclusion. Format of the abstract differs from one research organization to the other. The researchers are quite confused whether to adopt the institutional format or the required format by the research organizations where the paper is intended to be presented or published.

Table 10. Faculty self-assessment to research confidence in terms of other parts (references)

\begin{tabular}{llll}
\hline $\begin{array}{l}\text { I am confident in writing the other components in } \\
\text { writing research such as }\end{array}$ & $\begin{array}{l}\text { Weighted } \\
\text { Mean }\end{array}$ & Verbal Interpretation & Rank \\
\hline 1. accessing of available and updated materials & 2.73 & Agree & 1.5 \\
2. presentation/format of references in APA format & 2.73 & Agree & 1.5 \\
Composite Mean & 2.73 & Agree & \\
\hline
\end{tabular}

Legend: $3.50-4.00=$ Strongly Agree; $2.50-3.49=$ Agree; $1.50-2.49=$ Disagree; $1.00-1.49=$ Strongly Disagree

In terms of other components particularly writing the references as reflected in Table 10, respondents agreed that they are equally confident in accessing available and updated materials, as well as in the presentation of the entries, using APA style which both obtained 2.73 weighted mean. This indicates that the respondents have equal knowledge in accessing available and updated references and in presenting list of references, using APA style.

4.4 Relationship of Research Productivity to Research Organizational Support and Research Confidence Towards Research Writing

Table 11. Relationship of research productivity to research organizational culture and research confidence towards research writing

\begin{tabular}{lllll}
\hline Variables & $\lambda_{\mathrm{c}}^{2}$ & $\mathrm{p}$-value & Decision & Interpretation \\
\hline Organizational Support & & & & \\
Institutional & 11.458 & 0.323 & Accepted & Not Significant \\
$\begin{array}{l}\text { Departmental } \\
\text { Research Confidence towards }\end{array}$ & 9.396 & 0.495 & Accepted & Not Significant \\
$\begin{array}{l}\text { research writing in terms of: } \\
\text { Technical }\end{array}$ & 6.417 & 0.378 & Accepted & Not Significant \\
Major Parts & 7.700 & 0.463 & Accepted & Not Significant \\
Other Parts & 15.125 & 0.019 & Rejected & Significant \\
\hline
\end{tabular}

Legend: Significant at $\mathrm{p}$-value $<0.05$ 
As table 11 shows, only other parts (abstract and references) show significant relationship on research productivity since the obtained chi-square value of 15.125 is greater than the critical value and the resulted p-value of 0.019 is less than 0.05 level of significance, thus the null hypothesis of no significant relationship between research productivity and research confidence in terms of other parts is rejected. This means that they are confident with the other parts of the research process including writing the abstract and references as associated with developing research findings.

Therefore, this study further contends that, organizational support to research activities and their research confidence in writing the paper particularly the technical and major parts were all not indicators associated with their research productivity.

Self-motivation, essential skills and experience are the fundamental drivers that encourage faculty to do research. If there are no fundamental drivers despite institutional effort of providing other supportive factors, the University's endeavor will be fruitless (Lertputtarak, 2008). Providing an additional year of research may be an independent factor associated with research productivity (Cohen, Sherman , Kiet, Kapp, Osann, Chen, O'Sullivan, \& Chan, 2012) which may also be considered.

\subsection{Proposed Action Plan}

With the generated results, the action plan is hereby recommended focused on four major programs including standardization of research budget allocation, accessibility of online journals, faculty-to-faculty research mentoring and strategies to increase the confidence in research writing. The action plan is proposed to enhance the research productivity of the faculty members with appropriate utilization.

\section{Conclusions}

Based from the generated results and findings the following conclusions were drawn:

1) Faculty members of the College of Dentistry have low research productivity in terms of research output.

2) Generally, there is an average level of organizational support toward research productivity. Institutional support is higher compared to departmental support to motivate Dentistry faculty members to conduct research.

3) Respondents are most confident with the technical aspect including research paper format; grammar and sentence construction; research organization; and communication skills. On the other hand, they are least confident in writing the methodology of the paper of which the researchers are mostly guided by the assigned reader/referee and statistician.

4) Organizational support given by the university itself and the Department of College of Dentistry towards research activities and faculty members' confidence in writing the paper particularly the technical and major parts were not indicators associated with research productivity. However, they are confident with the other parts of the research process including writing the abstract and references as associated with developing research findings.

5) The proposed action plan is therefore devised for utilization and evaluation.

\section{Recommendations}

With the aforementioned findings and conclusions, the following recommendations are hereby endorsed:

\subsection{Institutional Support for Research Activities}

- The top management should allocate more budget to cater to the needs of the researchers in conducting the research project.

- Standardization of research budget allocated for a particular study based on the scope and nature is indispensable.

- Close coordination between the department concerned and the Research and Statistics Center on the possible online research database apart from the Academic One File.

\subsection{Departmental Support for Research Activities}

- The Dean of the department should continuously encourage the faculty to be involved in the conduct of research.

- $\quad$ Research mentoring among the faculty members must be integrated in the research culture 


\subsection{Faculty-Self Assessment to Research Confidence}

- Provide reinforcement trainings on research methodology in a regular basis with workshop and evaluation particularly on writing the instrument and determining appropriate statistical treatment.

6.4 Organizational Support and Research Confidence Affecting Research Productivity

- Since the present study is limited to research output of faculty member as surrogate for research productivity, further studies to include academic products/scholarly work such as publications, presentations, patented works, designs, and software are recommended to broaden the scope of the research productivity variable.

- The present study is likewise limited to organizational support and research confidence as determining factors in measuring research productivity. Therefore, further studies to include other factors such as demographic profile, time management, personal commitment, experience, self-motivation and others are also encouraged to determine what factors affecting the research productivity of the faculty members.

\subsection{Proposed Action Plan}

- The Research and Statistics Center in coordination with the Vice President for Academics and Research and the College Dean should closely monitor the implementation of the presented recommendations.

\section{References}

Alim, T., \& Diocolano, S. (2011). Research capability of state universities and colleges (SUC's) in region XII [Powerpoint Slides]. Retrieved from http://www.spumanila.edu.ph/data/FICL/FICL\%20Presentations/CS5\%20\%20Business\%20and\%20ICT/Al im_Diocolano\%20\%20Reseach\%20Capabilities\%20of\%20SUCs\%20in\%20Region\%20XII.pdf

Bower, M. (2010). Developing Pre-Service Teachers' Research Capabilities Using LAMS. Proceedings of the 5th International LAMS Conference 2010. Retrieved from http://lamsfoundation.org/lams2010sydney/papers.htm

Brambila, C., Veloso, F., \& Morgan, G. (2007). The determinants of research productivity: a study of Mexican researchers. Department of Engineering and Public Policy. Paper 133. Retrieved from http://repository.cmu.edu/epp/133

CHED Memorandum Order No. 25, Series of 1998, Priority Research Areas.

Clarke, L., \& Preston (2002). Benefits of research collaboration. Retrieved from http://www.rcr.emich.edu/module9/i4_benefits.html

Clemeña, R., \& Acosta, S. (2008). Developing research culture in Philippine higher education institutions: perspectives of university faculty, 184-197. Retrieved from Unesdoc database.

Cohen J., Sherman A., Kiet T., Kapp D., Osann K., Chen L, O'Sullivan P., \& Chan J. (2012). Characteristics of success in mentoring and research productivity - a case-control study of academic centers. Pubmed, 125(1), 8-13. http://dx.doi.org/10.1016/j.ygyno

Fabel, O., Hein, M., \& Hofmeister, R. (2008). Research productivity in business economics: an investigation of Austrian, German and Swiss universities. German Economic Review, 9(4), 506-531. Retrieved from http://www.univie.ac.at/ipersonal/forschung/pdfs/GEER_451.PDF

Gray, C. (2007). Research Competencies Framework. Faculty of General Dental Practice, The Royal College of Surgeons of England. Retrieved from http://www.fgdp.org.uk/_assets/pdf/research/research\%20competencies.pdf

Huang, H., \& Hsu, J. (2005). An evaluation of publication productivity in information systems:1999 to 2003. Communications of the Association for Information Systems, 15, 555-564. Retrieved from http://ai.arizona.edu/news/AIS05ISProductivity.pdf.

Idem, F., Berezi, I., \& Akuegwu, B. (2012). Research culture and effective university management in South-South Zone of Nigeria. Journal of Education and Practice, 3(9), 167-172. Retrieved from www.iiste.org.

Kotrlik, J., Barlett, J., Higgins, C., \& Williams, H. (2002). Factors associated with research productivity of agricultural education faculty. Journal of Agricultural Education, 43(3), 1-10. http://dx.doi.org/10.5032/jae.2002.03001. 
Lertputtarak, S. (2008). An investigation of factors related to research productivity in a public university in Thailand: A case strudy (unpublished dissertation). Victoria University, Melbourne, Australia.

LPU Manual. (Revision No. 6/June 2012).

Nichols, Allison. (2004). The effect of tenure and promotion policy on evaluation and research in extension. Journal of Extenstion, 42(2). Retrieved from http://www.joe.org/joe/2004april/rb1.php

Nuqui, A., \& Cruz, R. (2012). Determinants of faculty research productivity in Augustinian Higher Education Institutions in Luzon. IAMURE International Journal of Education, 3, 56-74. http://dx.doi.org/10.7718/iamure.ije.v3i1.191

Pateña, A. (2012). Research capability of LIMA faculty. [in press].

Wichian, S., Wongwanich, S. \& Bowarnkitiwong, S., (2009). Factors Affecting Research Productivity of Faculty Members in Government Universities: Lisrel and Neural Network Analyses. Kasetsart Journal (Soc. Sci), 30, 67-78. Retrieved from http://kasetsartjournal.ku.ac.th/kuj_files/2009/A0906251543307343.pdf

\section{Copyrights}

Copyright for this article is retained by the author(s), with first publication rights granted to the journal.

This is an open-access article distributed under the terms and conditions of the Creative Commons Attribution license (http://creativecommons.org/licenses/by/3.0/). 